\title{
CALL for PAPERS presented in J-K30thCeramics
}

We are pleased to inform you that selected papers presented at J-K30thCeramics are eligible to be published in specially Scheduled Issue of the Journal of The Ceramic Society of Japan, after standard peer review process and a decision of acceptance by the Editorial board. Authors who attend this conference and non- J-K30thCeramics participants are encouraged to submit their papers by February, $15^{\text {th }} 2014$ (deadline) at the web page below. Papers submitted by the deadline are expected to be published at the end of August 2014. In this particular issue, we will accept any research topics covering ceramic-related research.

The submission process can be seen at http://www.ceramic.or.jp/ihensyuj/toukou.html (in Japanese). For the submission, please access http://mc.manuscriptcentral.com/jcsj (in English) and follow the submission process as follows.

(1) Login using your account and password. If you do not have an account, please make new account.

(2) Push “Author Center”

(3) Click "here" button.

Author Resources

$\star$ Click here to submit a new manuscript

(4) Please select manuscript type, i.e., "Paper” or "review” or etc.,

(5) Please select "Scheduled Issue : J-K30

(6)

We are looking forward to receiving your papers.

Sincerely yours,

November 18, 2013 